these interventions has been demonstrated. These audits will continue on a regular basis to ensure maintenance of these standards, and improvement where necessary. A further audit of response to PCOC assessments will be conducted.

\section{AUDIT OF PATIENT BLOOD MANAGEMENT AT A SPECIALIST PALLIATIVE CARE UNIT}

Ed Duffy, Frances O'Mahony, Helen O'Connell, Aoibheann Na Chonfhaola, Colin Mortlock, Martina O'Reilly, Syed Qadri, Caroline Burke, Hilary O'Leary, Feargal Twomey. Milford Care Centre, Limerick

\subsection{6/spcare-2020-PCC.166}

Background Blood transfusion is a common practice in palliative care despite a dearth of evidence supporting its routine use in this setting.

Objectives

1. To review patient blood management at Milford Hospice.

2. To explore potential for prospective research in this area.

Methods Data pertaining to a purposive sample of transfusion events at Milford Care Centre that occurred in 2016 and 2017 was collected retrospectively from patient records and laboratory results. Data included demographic information, primary diagnosis, cause of anaemia, indication for transfusion, performance status, investigations such as haemoglobin and iron studies, and outcomes including 30-day outcomes and length of stay.

Results Of these 52 transfusion episodes included, 29 were regarding female patients and 34 were over the age of 65 . All patients had a diagnosis of malignancy, with bone metastases reported in 13 (25\%). Average Haemoglobin pre-transfusion was $7.21 \mathrm{~g} / \mathrm{dl}$. Iron studies were checked in ten cases.

2 or more units were transfused in all but 1 instance.

A beneficial response to transfusion was documented in 15 cases.

3 patients had haemoglobin checks after individual units of blood. 18 patients had haemoglobin checks within a week of the transfusion episode.

30-Day Outcome Post Transfusion: 46\% of patients had returned home; $33 \%$ of patients had died; $13 \%$ of patients remained in hospice; $8 \%$ other (long term care, missing data). Conclusions The lack of full investigation prior to transfusion demonstrates non-compliance with NICE standards and allows for potential overuse of blood products. Routine prescription of two units of blood without interval symptom reassessment or haemoglobin measurement may also contribute. These results were disseminated among clinical staff and an action plan was developed. An algorithm was developed for use in the inpatient palliative care setting and this is being implemented currently. Accompanying guideline development is also underway.

\section{PEACE PLAN: THE FUTURE OF ADVANCE CARE PLANNING IN THE ELDERLY}

N Palipane, KL Bettany, S Roy, S Gupta. Mid Essex Hospital Service NHS Trust, Farleigh Hospice

10.1136/spcare-2020-PCC.167

Background The PEACE (Proactive Elderly Advance Care) plan supports proactive planning of community care escalation through documenting patient wishes and communicating these with care stakeholders in primary and secondary care. It has been shown to reduce inappropriate re-admissions to hospitals at the end of life. Since September 2018, Broomfield Hospital has been promoting the use of the PEACE plan for elderly patients at the end of life being transferred to care homes. During rollout, it became apparent that there was a need to improve understanding amongst doctors about the indications for the document and their competence in its completion as well as related communication with patients and carers.

Aims To assess local impact of using the PEACE plan and competency in completion, derive relevant training needs, and coordinate the provision of multimodal education interventions.

Method A 1-year pilot study of PEACE plan completion and patient outcomes was implemented across two elderly care wards with Gold Standards Framework accreditation. An online confidence and knowledge questionnaire was completed by junior medical doctors and the results were used to model a training programme.

Results The majority of patients died within the year. Only $8 \%$ were readmitted, most were turned around within hours. The questionnaire indicates that, although most junior doctors were aware of the plan, only half had completed the form at the trust. Overall confidence in completing the plan was below expected and discussing artificial nutrition and hydration was a particular area of concern.

Conclusions The PEACE plan reduced inappropriate re-admissions to Broomfield hospital at the end of life. Specific training is required to improve knowledge and confidence of junior doctors before its introduction to all medical wards. This will be delivered as presentations, simulation workshops with a focus on communication skills, and multimedia instructional aids.

\section{HOSPICE AT HOME}

R Richardson, K Maw, D Willis. Severn Hospice

\subsection{6/spcare-2020-PCC.168}

Introduction Initially the 'Severn Hospice at Home Day Care Service' was created to provide specialist support and care to patients who were experiencing a crisis in their illness where additional nursing care could prevent hospital/hospice admission. The service needed a review to see if what it provided was what was needed by our local community.

Method Band 3 Healthcare Assistants were deployed to supplement other community teams supporting the assessment of that patient for a defined period of 72 hours. Evaluation of the service identified that most of these patients were in the last few weeks of life, requiring continual nursing care support. Subsequently the Hospice approached Complex Care (Continuing Health Care funding service) to become the palliative care provider of choice for Fast Track clients in the last 6 weeks of life.

Results End of life care is provided to all patients over the age of 18 regardless of diagnosis. The service provides one point of contact for all referrers seven days a week. Service quality standards already identified:

- Links to access to specialist advice - Outreach team, GP

- Prescribing and monitoring of medications

- Decrease in complaints received by complex care 